
\title{
R Research Square \\ Effect of the Variability of Wind Forcing on ENSO Simulation in an OGCM: Case of Canonical and Protracted Event
}

\section{Anika Arora ( $\square$ anika.cat@tropmet.res.in )}

Indian Institute of Tropical Meteorology https://orcid.org/0000-0003-4637-3446

\section{Research Article}

Keywords: El Niño, Surface wind forcing, Air-sea interaction, OGCM

Posted Date: August 23rd, 2021

DOl: https://doi.org/10.21203/rs.3.rs-468909/v2

License: (c) (i) This work is licensed under a Creative Commons Attribution 4.0 International License.

Read Full License

Version of Record: A version of this preprint was published at Theoretical and Applied Climatology on October 25th, 2021. See the published version at https://doi.org/10.1007/s00704-021-03816-5. 


\section{Abstract}

This study is an attempt to understand the onset and evolution of canonical El Niño ( 18-24 months; $\mathrm{CE}$ ) and protracted El Niño (> greater than 3 years; PE) compared to the normal state (NS) in an ocean model. Indo-Pacific warm pool indicates higher values of SST before the onset of strong canonical EI Niño compared to the normal state and protracted El Niño. The ocean model used in the study shows systematic SST bias in the Indo-Pacific Ocean with higher (cooler) values of temperature in western (eastern) Pacific during NS, CE, and PE exhibiting La Niña like conditions. The ocean model exhibits deeper thermocline depth in the western equatorial Pacific Ocean (PO) during PE and CE compared to NS indicating higher values of heat content (warm water volume). Despite the presence of higher warm water volume in the western PO before the onset of El Niño, the difference in the variability of surface wind forcing during the preceding months determines the type of El Niño. The interplay of surface wind forcing among the NS, PE, and CE states without altering the ocean state can modify the subsurface propagation in the equatorial Pacific Ocean. A change in longitudinal extent of upwelling Kelvin waves towards eastern PO along with the change in surface wind forcing decides the fate of El Niño in the eastern Pacific.

\section{Introduction}

At the beginning of the 21st century, the world experienced an 'extended' El Niño during 2014-16 which falls under the category of protracted ENSO (El Niño Southern Oscillation) events (Allan et al. 2020). A typical (canonical) El Niño event (CE) lasts for 18-24 months and makes a transition to La Niña or neutral state within a year after the peak phase of the event occurring mostly in the boreal winter whereas prolonged or protracted event of El Niño persisting for more than 3 years is not followed by a neutral or cold phase event (Rasmusson and Carpenter 1983; Allan and D'Arrigo 1999a). Strong easterly wind bursts during June-July 2014 led to the weakening of the eastern equatorial Pacific warming in 2014 and the build-up of equatorial heat content provided favorable background conditions for the formation of strong El Niño in 2015 (Levine and McPhaden 2016). (Kakatkar et al. 2018) using reanalysis data and model experiments compared two strong El Niños of 1997 and 2015 and found that not the strength of El Niño, but large-scale wind forcing, and the associated ocean dynamics govern the strength of La Niña in the following year. The equatorial PO witnessed peculiar characteristics in terms of ocean dynamics, zonal phase propagation, westerly wind bursts, discharge-recharge during this extreme ENSO compared to previous El Niño events (Gasparin and Roemmich 2016; Levine and McPhaden 2016). Each ENSO exhibits diverse behavior in terms of mean state and interannual variability. The variable relative contribution of physical processes underlying the different ENSO can lead to different types of SST anomalies at different longitudes in the equatorial Pacific (Capotondi et al. 2015; Chen et al. 2016).

Wind stress forcing plays a key role in determining the size and timing of these ENSO events (Bjerknes, 1969). Westerly wind bursts (WWB) can advect the western Pacific warm pool into the central Pacific via the generation of downwelling Kelvin waves along the thermocline across the equatorial Pacific Ocean (McPhaden 1999). Multiple WWBs that occur during boreal summer and fall months throughout the 
growth phase of the El Niño event can trigger strong El Niño events (McPhaden 1999; Eisenman et al. 2005). Another necessary but not sufficient condition for the onset of ENSO is a buildup of anomalous warm water volume (WWV) over the upper part of the tropical Pacific Ocean (Wyrtki 1985; Jin 1997; Meinen and McPhaden 2000). This build-up of WWV along with the presence of WWBs during boreal spring and summer monsoon months over the western Pacific Ocean can lead to an El Niño event in the following winter months (McPhaden 2003; Yu and Kao 2007).(Levine and McPhaden 2016) examined WWV and WWB (Westerly wind bursts) anomalies over the upper part of the tropical Pacific Ocean as a predictor of the El Niño event. They found that both strong wind stress forcing and WWV anomaly is critical for the extreme El Niño events (1982, 1997, and 2015). Also, protracted ENSO events (1990 and 2014) show unusually large WWV anomalies during the boreal spring season in the absence of significant wind stress forcing during the preceding boreal summer and fall months (Allan and D'Arrigo 1999b; Levine and McPhaden 2016; Arora and Kumar 2019). The effect of wind stress forcing on WWV is a function of the current state of the ocean-atmosphere system and the time of year (Fedorov et al. 2015). WWBs occurring west of the dateline in the boreal winter months led to a build-up of WWV in 1990 and 2014.

Arora and Kumar (2019) using observations and reanalysis data for the period of 1980-2010, attempted to understand the process of evolution and decay of the two types (i.e., canonical and protracted) of El Niño's. This study hypothesized that frequently (occasionally) occurring weak (strong) westerly wind bursts over the western PO and Maritime continent before the onset of El Niño can result in a protracted (canonical) El Niño. This study assumed the heat content over Western Pacific to be the same before the onset of both El Niño types. The presence of anomalous easterlies in the western equatorial PO during the decay phase of CE events cools SST in eastern PO via the generation of upwelling Kelvin waves. However, weak localized warming in $\mathrm{IO}$ is incapable of generating a significant atmospheric response in the form of easterlies. Though the ENSO variability is well captured by many climate models, there still exists biases in simulation and prediction of ENSO (Ren et al. 2016; Zheng et al. 2016). Earlier studies have emphasized the forcing effects of wind stress, heat flux, and freshwater flux forcing effect on ENSO modulations in the coupled system (Gasparin \& Roemmich, 2016; Waliser et al., 1994; Xie \& Philander, 1994). This study focuses on the interchange of horizontal wind forcing at the ocean surface without altering the mean state of the ocean during different states of the ocean (protracted ENSO, canonical ENSO, and normal state; explained in detail in Sect. 2) in an ocean general circulation model (OGCM; MOM5.1.0) to verify the hypothesis proposed in (Arora and Kumar 2019). This paper is organized as follows: Sect. 2 describes the model experiment used in the study. Sections 3 discusses the results of the study and Sect. 4 summarized the major findings of the study.

\section{The Model Used And Details Of The Experiment}

The Ocean General Circulation Model (OGCM) used in this study is the Geophysical Fluid Dynamics Laboratory (GFDL) Modular Ocean Model version 5.1.0 (Griffies et al. 2004). This model provides a numerical representation of the ocean's primitive equations for studying the ocean climate system. The model used in this study is a global model with $1^{\circ}$ zonal resolution. The meridional resolution varies from 
$0.33^{\circ}$ at the equator to $0.67^{\circ}$ up to the tropics and gradually increasing to $1^{\circ}$ towards the pole. There are 50 vertical levels from 0 to $5000 \mathrm{~m}$ with $10 \mathrm{~m}$ resolution in the first $250 \mathrm{~m}$. The vertical coordinate system used in the model is Pressure-based. MOM5 includes the Arakawa C-grid option as well as a dynamically interacting Lagrangian sub-model.

MOM5 is initialized using the annual climatology of temperature and salinity from (Levitus 1998) and forced with the Coordinated Ocean-ice Reference Experiments (GFDL-CORE v2) Normal Year Forcing of down-welling shortwave and longwave radiation, $10 \mathrm{~m}$ surface wind fields, specific humidity, air temperature, surface pressure and surface precipitation (Large and Yeager 2009) and spun up for 100 years. From that state, the model is forced with CORE v2 inter-annually varying forcing (IAF) for the period 1948-2009. This is termed as control run (Ctrl) in the study. For wind sensitivity experiments with OGCM, the model state in the control run at the end of the year 1957 (pre-NS), the year 1979 (pre-CE), and the year 1989 (pre-PE) are used as reference states for experimental runs. The reason for referencing these years as pre-NS, pre-CE, and pre-PE is explained in Sect. 3.1. The model is integrated for five years from 1990 to 1994 (PS) from the pre-PE state using wind forcing used during the canonical period (CE) and normal period (NS) in the control run. This is termed as exp1 and exp2 respectively in the study. Similar experiments are performed by interchanging the surface wind forcing during the CE (NS) period with the surface wind forcing used during the control run in PE and NS (CE). Details of all OGCM experiments are provided in Table 1. The model results are compared further with instrument subsurface ocean temperature data EN4-v4.2.1 from Met Office Hadley Centre for the period 1948-2009 (Good et al. 2013).

Table 1: List of experiments performed with the OGCM.

\begin{tabular}{||c|c|c||}
\hline EXP No & Simulation Period & Wind Forcing \\
\hline \hline $\exp 1$ & $1990-94$ & $1980-84$ \\
\hline $\exp 2$ & $1990-94$ & $1958-62$ \\
\hline $\operatorname{exp3}$ & $1980-84$ & $1990-94$ \\
\hline $\exp 4$ & $1980-84$ & $1958-62$ \\
\hline $\operatorname{exp5}$ & $1958-62$ & $1990-94$ \\
\hline $\operatorname{exp6}$ & $1958-62$ & $1980-84$ \\
\hline \hline
\end{tabular}

\section{Results And Discussion}

\subsection{Mean Ocean state during different types of El Niño}


A warming event in the Pacific Ocean is termed as El Niño only when 3-month running means of the areaaveraged SST anomaly over the Niño 3.4 region $\left(170^{\circ} \mathrm{W}-120^{\circ} \mathrm{W}, 5^{\circ} \mathrm{S}-5^{\circ} \mathrm{N}\right)$ crosses a threshold of $0.5^{\circ} \mathrm{C}$ for at least five consecutive seasons. Climate Prediction Center (CPC-NOAA) uses the same definition for its operational forecasts. An El Niño can further be categorized into canonical ENSO and protracted ENSO based on the persistence of area-averaged SST anomaly over the Niño 3.4 region. If a positive SST anomaly during an El Niño event lasts for more (less) than 3 consecutive years, the event is termed as protracted (canonical) El Niño (Allan and D'Arrigo 1999b, a). Figure 1 shows the time series of the seasonal mean (3-month running mean) of SST anomaly averaged over Niño 3.4 region for the period 1948-2009. Identification of El Niño events is done following the standard definition of Climate Prediction Center (CPC-NOAA). Different ocean states are chosen based on temporal temperature evolution in the eastern PO. Observed SST anomaly averaged over Niño 3.4 region shows the transition of strong ENSO in the year 1982-83 into a La Nina in the following year 1983-84, 1984-85. This state is termed as canonical ENSO (1980-84; CE) state in this study. SST anomaly averaged over Niño 3.4 region during 1991-92 does not show the transition of El Niño to La Nina state instead weak El Niño continues in the following year too (Allan and D'Arrigo 1999b; Arora and Kumar 2019). This state of the equatorial ocean is termed protracted ENSO state (1990-94; PE). During the period 1958-62, there does not exist either El Niño or La Nina in the eastern Pacific. This state is termed as Normal Ocean state (1958-62; NS). Ocean state before the start of NS (December 1957), CE (December 1979), and PE (December 1989) is termed as pre-NS, pre-CE, and pre-PE respectively.

Figure 2(a-c) shows mean SST during pre-NS, pre-CE, and pre-PE state in the model control simulation of the model respectively. The difference in the spatial structure of SST in the tropical Indo-Pacific region shows the different values of heat content before the onset of distinct types of ENSO. Each state exhibits a peculiar signature of zonal extent and position of Indo-Pacific warm pool (SST greater than $28^{\circ} \mathrm{C}$; (Gadgil et al. 1984; Graham and Barnett 1987). Oceanic anomalies before the onset of El Niño over the western Pacific are related to the strengthening of the trades, and the accumulated warm water flows eastward in the form of Kelvin waves to initiate an El Niño event (Wyrtki 1975). Also, the cold tongue in the equatorial eastern Pacific is more extended towards the international dateline in the pre-PE state compared to the pre-NS and pre-CE state. Figure 2(d\&e) shows the difference of mean SST of pre-CE and pre-PE state from the pre-NS state as shown in Fig. 2(a-c). Higher values of SST are seen in the IndoPacific warm pool during the pre-CE state before the onset of strong canonical ENSO compared to the pre-NS state. Higher values of SST during pre-CE and pre-PE state compared to pre-NS are seen over the western PO. Bay of Bengal region shows cooler SST during pre-PE state compared to pre-NS and pre-CE state. A comparison of pre-CE and pre-PE state shows the higher SST (by $2^{\circ} \mathrm{C}$ ) in the cold tongue region during pre-CE conditions with cooler SST over the western PO (Fig. 2(f)). It implies that before the onset of the protracted ENSO event, heating is confined to the western Pacific with additional cooling along the eastern Pacific due to the presence of trade winds in the eastern Pacific.

Figure 3 shows the mean SST during NS, CE, and PE events for model control run (Fig. 3(a-c)) and observations (Fig. 3(d-f)) and their respective differences (Fig. 3(g-i)). Higher values of SST are seen over the Indo-Pacific warm pool region with the extent of the warm pool from the eastern Indian Ocean to the 
western Pacific Ocean. A comparison of mean SST in model control run and observations during NS shows warmer (cooler) SST in western (eastern) PO near the dateline in the model control run. Also, mean SST is cooler over the Arabian Sea and Bay of Bengal region in the model control run compared to observed SST. This structure of model bias is systematic and appears during CE as well as PE with a small difference in magnitude. This systematic bias in SST in the Pacific Ocean in OGCM leads to an increased east-west gradient of SST along the equator in the Pacific Ocean compared to observations. Since zonal SST gradients are coupled to atmospheric zonal circulation, known as the Walker circulation (Allan and D'Arrigo 1999b; Levine and McPhaden 2016; Arora and Kumar 2019); any change in zonal SST gradient can further alter the zonal tilt of the oceanic thermocline and the strength of equatorial upwelling. Figure 4 shows the difference of SST for the mean states of CE, PE, and NS states for the model control run and observations as shown in Fig. 3. Difference of mean SST during CE state from NS and PE state in the model control run simulate warmer SST with wider horizontal extent over Indo-Pacific warm pool along with basin-wide warmer SST in the Indian Ocean compared to observations. The difference of mean SST during PE state from NS state shows cooler SST over the equatorial easterncentral PO. This is due to the presence of anomalous easterly trade winds during protracted ENSO events(Levine and McPhaden 2016).

Figure 5 shows the mean D20 during NS, CE, and PE events for model control run (Fig. 5(a-c)) and observations (Fig. 5(d-f)) and their respective differences (Fig. 5(g-i)). OGCM can simulate the subsurface structure of the thermocline very well consistent with the surface. Systematic warm SST bias present over Indo-Pacific warm pool and western PO is also seen at subsurface levels in model control simulation. Model control run can capture spatial structure of shallow thermocline regions in the Western Indian Ocean (IO) (the Seychelles Dome) and eastern Pacific (Yokoi et al. 2008) (Fig. 5). However, the value of D20 in deeper thermocline regions has a positive bias in western and southern tropical IO and the northern Pacific during all types of ENSO events (NS, CE, and PE). This positive bias is strongest in the case of PE events. Also, D20 is underestimated (overestimated) in NS and CE (PE) events in the southwestern and central Pacific. Figure 6 shows the difference of mean D20 for CE, PE, and NS states for the model control run and observations as shown in Fig. 5. Indian ocean shows a relatively deeper thermocline mainly throughout the basin during CE and PE events compared to NS with shallower D20 during CE event in observations as well as model control run. A deeper (shallower) thermocline depth in western PO during PE and CE compared to NS is a qualitative measure of the higher value of WWV acting as a precursor for the initiation of ENSO (Arora and Kumar 2019). Also, higher values of D20 are seen over the western Pacific during PE compared to CE events consistent with previous studies (Levine and McPhaden 2016; Arora and Kumar 2019).

\subsection{Preconditioning of equatorial Pacific for triggering of ENSO}

Figure 7 shows the mean zonal wind forcing anomaly at $10 \mathrm{~m}$ averaged over equatorial Western Pacific $\left(100-200^{\circ} \mathrm{E}, 2.5^{\circ} \mathrm{S}-2.5^{\circ} \mathrm{N}\right)$ for NS, CE, and PE states. Wind forcing for NS indicates the dominant presence 
of westerlies (positive values) over the Western Pacific region embedded with easterlies (negative values). Zonal wind forcing anomaly at $10 \mathrm{~m}$ shows predominant westerlies with maximum values (up to $6 \mathrm{~m} / \mathrm{s}$ ) at the end of the year 1982 yielding a peak of strong El Niño. Along with the change in phase of SST anomalies averaged over the Niño 3.4 region, zonal wind anomalies over Western Pacific also change to easterlies following (Bjerknes 1969)'s positive feedback in equatorial PO. Wind forcing anomaly during PE events hovers around mean value with values ranging from -4 to $4 \mathrm{~m} / \mathrm{s}$. Figure 8 shows the histogram of wind forcing anomaly shown in Fig. 7 for NS, CE, and PE states. The distribution of zonal wind anomaly averaged over the western Pacific Ocean follows a normal distribution for PE state. However, this distribution is slightly skewed towards positive values indicating the presence of more anomalous westerlies during NS, and skewness towards positive values increases more during CE compared to NS. This implies that the difference in zonal wind forcing at the surface in the western Pacific before the onset of El Niño can trigger different states of ENSO in the eastern Pacific.

Warm water volume (WWV) is defined as the volume of water up to $20^{\circ} \mathrm{C}$ isotherm depth and is an important predictor of ENSO (Meinen and McPhaden 2000; Bunge and Clarke 2014). WWV is calculated for the equatorial eastern PO (EP; $5^{\circ} \mathrm{S}-5^{\circ} \mathrm{N}, 80^{\circ} \mathrm{W}-155^{\circ} \mathrm{W}$ ), western PO (WP; $5^{\circ} \mathrm{S}-5^{\circ} \mathrm{N}, 120^{\circ} \mathrm{E}-155^{\circ} \mathrm{W}$ ), and total PO (TP; $\left.5^{\circ} \mathrm{S}-5^{\circ} \mathrm{N}, 120^{\circ} \mathrm{E}-80^{\circ} \mathrm{W}\right)$. Figure 9 compares WWV anomalies calculated for the model control run with WWV calculated using EN4-v4.2.1 for TP, EP, and WP. Model control simulation well captures the WWV over the WP region with a very high correlation with observations for NS, CE, and PE $(0.79,0.8$, and 0.75 respectively). The value of the correlation of WWV over TP (EP) among observations and model control run is $0.32,0.67$, and $0.41(0.3,0.19$, and 0.54$)$ for NS, CE, and PE respectively. All values except 0.19 are statistically significant at $90 \%$. WWV anomaly averaged over TP and WP remains below normal the climatology for NS for model control run as well as observations indicating no build-up of heat content in TP and WP. WWV averaged over EP hovers around the mean value during NS indicating the presence of no ENSO-like conditions in EP. During the CE event, WWV averaged over TP and WP increased before the peak of the El Niño event and then decreased as El Niño made the transition to La Nina. WWV averaged over CE starts increasing from the beginning of 1982. It reaches maximum value around the end of 1982 and then reverses its sign with the transition of El Niño to La Nina. (Arora and Kumar 2019) highlighted a high value of correlation (0.8) between SST anomaly averaged over Niño 3.4 region and WWV anomaly averaged over EP. Discharge of warm water from WP towards EP leads to initiation of El Niño with a lead period of 6-10 months and WWV averaged over EP leads Niño 3.4 SST anomaly by 1-2 months. WWV averaged over TP and WP shows above normal values along with an increasing trend during PE. This increasing trend in anomalous WWV is due to the build-up of heat content in WP due to the presence of weak westerly or easterly winds during boreal summer and fall months (Allan and D'Arrigo 1999b; Levine and McPhaden 2016; Arora and Kumar 2019). Also, anomalous WWV averaged over EP remains positive indicating persistent El Niño type conditions throughout the PE duration (199094) consistent with the previous study (Arora and Kumar 2019) for both model control run as well as observations. 


\subsection{Changes in surface and subsurface parameters during model experiments}

Figure 10 shows ocean temperature anomaly averaged over Niño 3.4 region for different layers of the upper ocean for model control as well as six experimental runs overlaid by observed temperature anomaly. The value of the correlation of ocean temperature anomaly averaged over Niño 3.4 region averaged over layers of upper ocean (5-100m, 100-200m, and 200-300m) between model control run and observations is $0.81,0.61$, and 0.19 respectively. These correlation values are statistically significant at $99 \%$. A significant value of correlation between temperature anomaly simulated by OGCM averaged over these layers with observed temperature anomaly implies that the model can capture temperature in the upper ocean over Niño 3.4 region well. Temperature anomalies in the near-surface layer $(5-100 \mathrm{~m})$ in the upper ocean are better captured compared to the deeper layer of the upper ocean (200-300m). Forcing of normal ocean state (NS:1958-62) with horizontal wind forcing at 10m during protracted ENSO (PE:199094; exp5) years and canonical (CE:1980-84; exp6) ENSO years perturb mean anomalous state to have variability of $P E$ and $C E$ state. A similar change in variability of $C E(P E)$ state compared to model control run is observed when forced with horizontal winds of PE (CE) and NS respectively. Table 1 provides a list of experiments performed using OGCM. This interplay of horizontal wind forcing among the NS, PE, and CE states of the ocean shows the importance of strength and variability of winds as a governing factor in the onset and type of ENSO. Subsurface layers $(100-200 \mathrm{~m}, 200-300 \mathrm{~m})$ in the upper ocean over Niño 3.4 region also vary following surface layers due to shallow thermocline depth over the equatorial eastern Pacific Ocean (Zelle et al. 2004).

Figure 11 shows the ocean temperature anomaly averaged over $5^{\circ} \mathrm{S}-5^{\circ} \mathrm{N}$ up to $300 \mathrm{~m}$ depth for $\mathrm{PE}, \mathrm{CE}$, and NS for model simulations and observations. Observed PE event shows the strengthening of positive anomalies near the surface in the eastern PO extending up to date line along with negative subsurface anomalies in the western PO. Compared to PE, the extent of positive anomalies is confined to the eastern Pacific only for CE event. However negative subsurface anomalies indicating the presence of upwelling Kelvin waves are more zonally extended in CE event compared to PE event. NS does not show any significant surface or subsurface anomalies. Model control run overestimates the ocean temperature anomalies during NS and PE compared to observations. Though the zonal extent of anomalies from the eastern Pacific in the model control run matches well with observations, subsurface anomalies from the western Pacific are far more zonally extended and strengthened in model control run compared to observations especially in the case of PE and NS. Change of zonal wind forcing over the pre-PE state to the wind forcing used during the CE period (exp1) shows a reduction in the magnitude of subsurface temperature anomalies. Also, the zonal extent of positive anomalies from the eastern Pacific decreases in the case of exp1 compared to model control run and observations. Forcing the pre-PE state with wind forcing during NS (exp2) completely diminishes the ENSO-like conditions in the equatorial Pacific. Similarly forcing the pre-CE state with wind forcing during PE (NS) show the strengthened (diminished) subsurface signature of PE (NS). Forcing of pre-NS state with wind forcing of PE (exp5) and CE (exp6) 
shows weakened PE and CE-like structure due to the presence of La Nina-like conditions due to systematic bias during NS in the model control run.

\section{Conclusions}

Previous studies have reported six protracted (also termed as persistent) El Niño events (1894-97, 191114, 1939-42, 1990-95, 2002-06, and 2014-16) since 1876 (Allan and D'Arrigo 1999a; Arora and Kumar 2019; Allan et al. 2020). It is certain from these records that the frequency of occurrence of these protracted events has increased during the last two decades. This study is an attempt to understand the life cycle of the two primitive types of El Niño (canonical and protracted) using an ocean model. Anomalous westerlies along with the presence of anomalous heat content over the western PO and Maritime continent lead to the onset of El Niño in the eastern Pacific. The magnitude and frequency of occurrence of these anomalous westerlies determine the type of ENSO state and associated teleconnections (Arora and Kumar 2019). Three different states termed as canonical ENSO (CE; 1980-84), protracted ENSO (PE;1990-94), and normal State (NS;1958-62) spanning over 5 years are identified using the standard definition of EI Niño by CPC-NOAA. Each type of state exhibits a peculiar structure of surface and subsurface temperature in tropics before the onset of ENSO. Model control run simulates higher values of SST over western PO along with more zonally extended cold tongue in the eastern PO before the onset of the PE compared to CE and NS state consistent with previous studies (Levine and McPhaden 2016). The ocean model used in this study exhibits systematic bias at the surface as well as subsurface yielding an increased east-west gradient of SST along the equator in the Pacific Ocean compared to observations. There is a difference in the distribution of anomalous surface forcing over western PO during different states. While PE state follows Normal distribution; NS and CE state show skewness towards positive values indicating the presence of more anomalous westerlies during NS and CE. Model experiments are performed by interchanging the surface wind forcing among different ENSO states without altering the ocean state before the onset of El Niño. While chosen initial ocean state keeps the memory of the mean state, the selection of the applied surface wind forcing chosen among the three types of forcings determines the variability of the upper ocean. Wind forcing at the surface in the boreal summer months can determine the fate of ongoing subsurface EI Niño and associated teleconnections. Improved understanding of model biases in the upper ocean and surface wind forcing in climate models can help in the understanding of the processes involved during the evolution and decay phase of El Niño.

\section{Declarations}

\section{Acknowledgments}

The authors thank the Director IITM for his full support. The authors thank NCAR for making available the NCL software. All the data sources are duly acknowledged. Indian Institute of Tropical Meteorology (IITM) is fully funded by the Ministry of Earth Sciences (MoES), Government of India, New Delhi. Pratyush HPC facility at IITM is duly acknowledged. 


\section{Conflict of interest}

The author declare that I have no conflict of interest.

\section{Funding}

This research is carried out at IITM Pune. No additional funding support was received.

\section{Authors' contributions}

Anika Arora carried out all the work related to this manuscript.

\section{Availability of data and material}

The instrument subsurface ocean temperature data for the period 1948-2009 (EN4-v4.2.1) is taken from Met Office Hadley Centre. This data is available at https://www.metoffice.gov.uk/hadobs/en4/downloaden4-2-1.html.

\section{Code availability}

All the calculations and plots have been done using various tools such as NCL, Grads, and CDO.

\section{Ethics approval}

The manuscript has not been submitted to more than one journal for simultaneous consideration. The manuscript has not been published elsewhere previously.

Consent to participate Not Applicable

Consent for publication Not Applicable

\section{References}

1. Allan RJ, D’Arrigo RD (1999a) “Persistent” ENSO sequences: How unusual was the 1990-1995 El Nino? Holocene 9:101-118

2. Allan RJ, D'Arrigo RD (1999b) “Persistent” ENSO sequences: How unusual was the 1990-1995 El Nino? Holocene 9:101-118. https://doi.org/10.1191/095968399669125102

3. Allan RJ, Gergis J, D'Arrigo RD (2020) Placing the AD 2014-2016 'protracted' El Niño episode into a long-term context. Holocene 30:90-105. https:// doi.org/10.1177/0959683619875788

4. Arora A, Kumar S (2019) What makes protracted El Niño to last longer than canonical El Niño? Theoretical and Applied Climatology 136:587-603. https://doi.org/10.1007/s00704-018-2503-8

5. Bjerknes J (1969) Atmospheric Teleconnections From the Equatorial Pacific 1 . Monthly Weather Review 97:163-172. https://doi.org/10.1175/1520-0493(1969)097<0163:atftep>2.3.co;2 
6. Bunge L, Clarke AJ (2014) On the warm water volume and its changing relationship with ENSO. Journal of Physical Oceanography 44:1372-1385. https://doi.org/10.1175/JPO-D-13-062.1

7. Capotondi A, Wittenberg AT, Newman M, et al (2015) Understanding enso diversity. Bulletin of the American Meteorological Society 96:921-938. https://doi.org/10.1175/BAMS-D-13-00117.1

8. Chen S, Wu R, Chen W, et al (2016) Genesis of westerly wind bursts over the equatorial western Pacific during the onset of the strong 2015-2016 El Niño. Atmospheric Science Letters 17:384-391. https://doi.org/10.1002/asl.669

9. Eisenman I, Yu L, Tziperman E (2005) Westerly wind bursts: ENSO's tail rather than the dog? Journal of Climate 18:5224-5238. https://doi.org/10.1175/JCLI3588.1

10. Fedorov A v., Hu S, Lengaigne M, Guilyardi E (2015) The impact of westerly wind bursts and ocean initial state on the development, and diversity of El Niño events. Climate Dynamics 44:1381-1401. https://doi.org/10.1007/s00382-014-2126-4

11. Gadgil S, Joseph P v., Joshi N v. (1984) Ocean-atmosphere coupling over monsoon regions. Nature 312:. https://doi.org/10.1038/312141a0

12. Gasparin F, Roemmich D (2016) The strong freshwater anomaly during the onset of the $2015 / 2016$ El Niño. Geophysical Research Letters 43:6452-6460. https://doi.org/10.1002/2016GL069542

13. Good SA, Martin MJ, Rayner NA (2013) EN4: Quality controlled ocean temperature and salinity profiles and monthly objective analyses with uncertainty estimates. Journal of Geophysical Research: Oceans 118:6704-6716. https://doi.org/10.1002/2013JC009067

14. Graham NE, Barnett TP (1987) Sea surface temperature, surface wind divergence, and convection over tropical oceans. Science 238:. https://doi.org/10.1126/science.238.4827.657

15. Griffies SM, Harrison MJ, Pacanowski RC, Rosati a (2004) A technical guide to MOM4. GFDL Ocean Group Tech Rep 5:371

16. Jin FF (1997) An equatorial ocean recharge paradigm for ENSO. Part I: Conceptual model. Journal of the Atmospheric Sciences 54:811-829. https://doi.org/10.1175/15200469(1997)054<0811:AEORPF>2.0.CO;2

17. Kakatkar R, Gnanaseelan C, Deepa JS, et al (2018) Role of ocean-atmosphere interactions in modulating the 2016 La Niña like pattern over the tropical Pacific. Dynamics of Atmospheres and Oceans 83:100-110. https://doi.org/10.1016/j.dynatmoce.2018.07.003

18. Large WG, Yeager SG (2009) The global climatology of an interannually varying air - Sea flux data set. Climate Dynamics 33:341-364. https://doi.org/10.1007/s00382-008-0441-3

19. Levine AFZ, McPhaden MJ (2016) How the July 2014 easterly wind burst gave the 2015-2016 El Niño a head start. Geophysical Research Letters 43:6503-6510.

https://doi.org/10.1002/2016GL069204

20. Levitus Sydney (1998) World ocean database 1998

21. McPhaden MJ (1999) Genesis and evolution of the 1997-98 El Nino. Science 283 
22. McPhaden MJ (2003) Tropical Pacific Ocean heat content variations and ENSO persistence barriers. Geophysical Research Letters 30:1480. https://doi.org/10.1029/2003GL016872

23. Meinen CS, McPhaden MJ (2000) Observations of warm water volume changes in the equatorial Pacific and their relationship to El Nino and La Nina. Journal of Climate 13:3551-3559. https://doi.org/10.1175/1520-0442(2000)013<3551:00WWVC>2.0.CO;2

24. Rasmusson EM, Carpenter TH (1983) The relationship between eastern equatorial Pacific sea surface temperatures and rainfall over India and Sri Lanka. Monthly Weather Review 111:517-528. https://doi.org/10.1175/1520-0493(1983)111<0517:TRBEEP>2.0.CO;2

25. Ren HL, Zuo J, Jin FF, Stuecker MF (2016) ENSO and annual cycle interaction: the combination mode representation in CMIP5 models. Climate Dynamics 46:. https://doi.org/10.1007/s00382-015-2802-z

26. Waliser DE, Blanke B, Neelin JD, Gautier C (1994) Shortwave feedbacks and El Nino-Southern Oscillation: forced ocean and coupled ocean-atmosphere experiments. Journal of Geophysical Research 99:. https://doi.org/10.1029/94jc02297

27. Wyrtki K (1985) Water displacements in the Pacific and the genesis of El Nino cycles. Journal of Geophysical Research 90:. https://doi.org/10.1029/jc090ic04p07129

28. Wyrtki K (1975) El Niño-The Dynamic Response of the Equatorial Pacific Oceanto Atmospheric Forcing. Journal of Physical Oceanography 5:. https://doi.org/10.1175/15200485(1975)005<0572:entdro>2.0.co;2

29. Xie S -Ping, Philander SGH (1994) A coupled ocean-atmosphere model of relevance to the ITCZ in the eastern Pacific. Tellus A 46:. https://doi.org/10.1034/j.1600-0870.1994.t01-1-00001.x

30. Yokoi T, Tozuka T, Yamagata T (2008) Seasonal variation of the Seychelles Dome. Journal of Climate 21:. https://doi.org/10.1175/2008JCLI1957.1

31. Yu JY, Kao HY (2007) Decadal changes of ENSO persistence barrier in SST and ocean heat content indices: 1958-2001. Journal of Geophysical Research Atmospheres 112:. https://doi.org/10.1029/2006JD007654

32. Zelle H, Appeldoorn G, Burges G, van Oldenborgh GJ (2004) The relationship between sea surface temperature and thermocline depth in the eastern equatorial Pacific. Journal of Physical Oceanography 34:643-655. https://doi.org/10.1175/2523.1

33. Zheng Z, Hu ZZ, L'Heureux M (2016) Predictable Components of ENSO Evolution in Real-time MultiModel Predictions. Scientific Reports 6:35909. https://doi.org/10.1038/srep35909

\section{Figures}




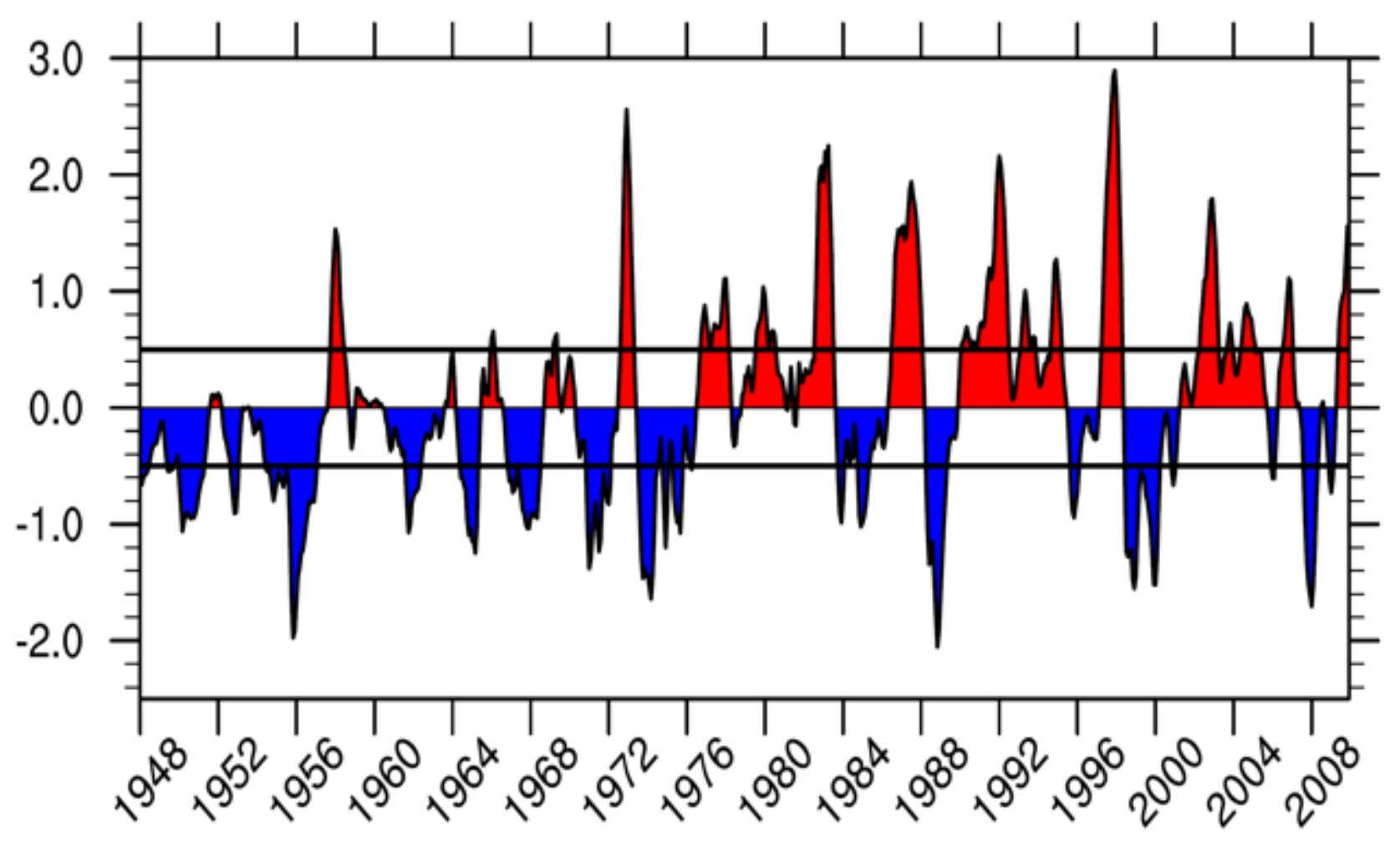

Figure 1

Seasonal running mean (3 months) of SST anomalies averaged over Niño 3.4 region for the period 1948-2009. The solid black line represents the threshold value for El Niño/La Niña. 


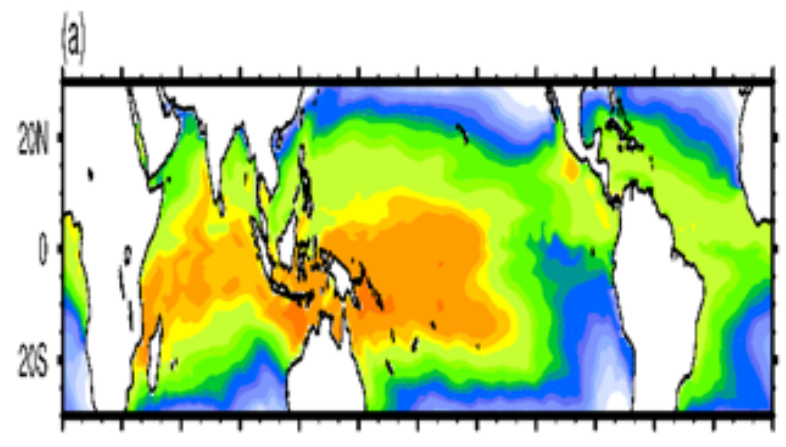

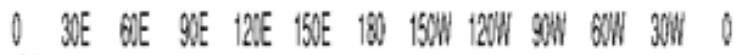
(b)

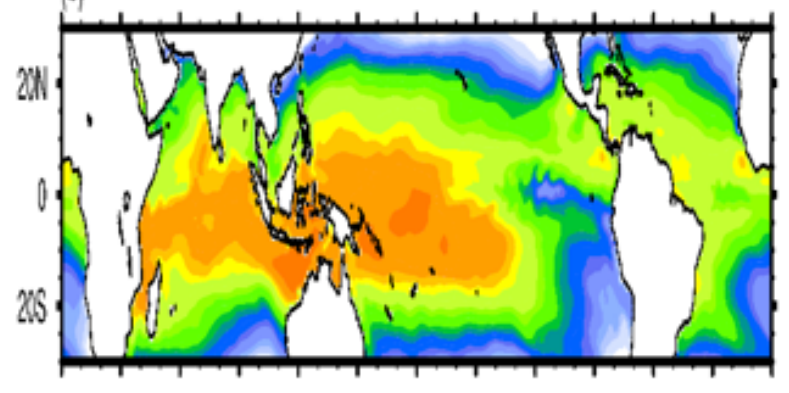

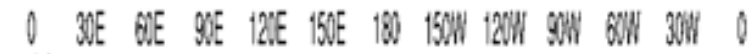

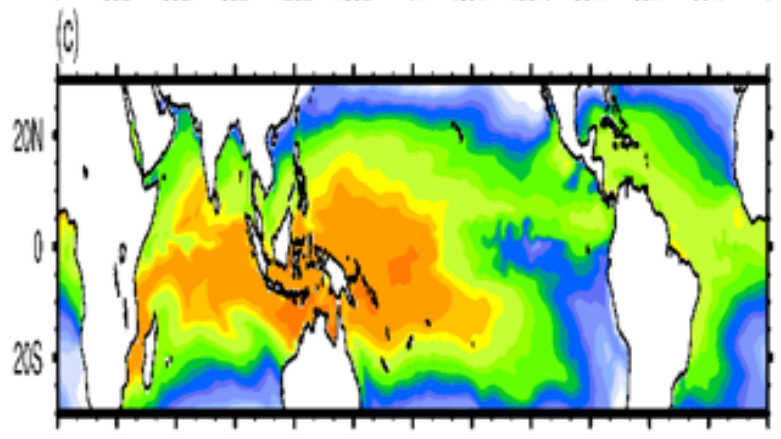

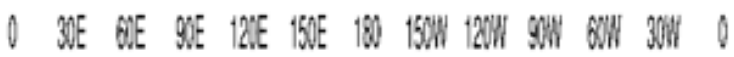
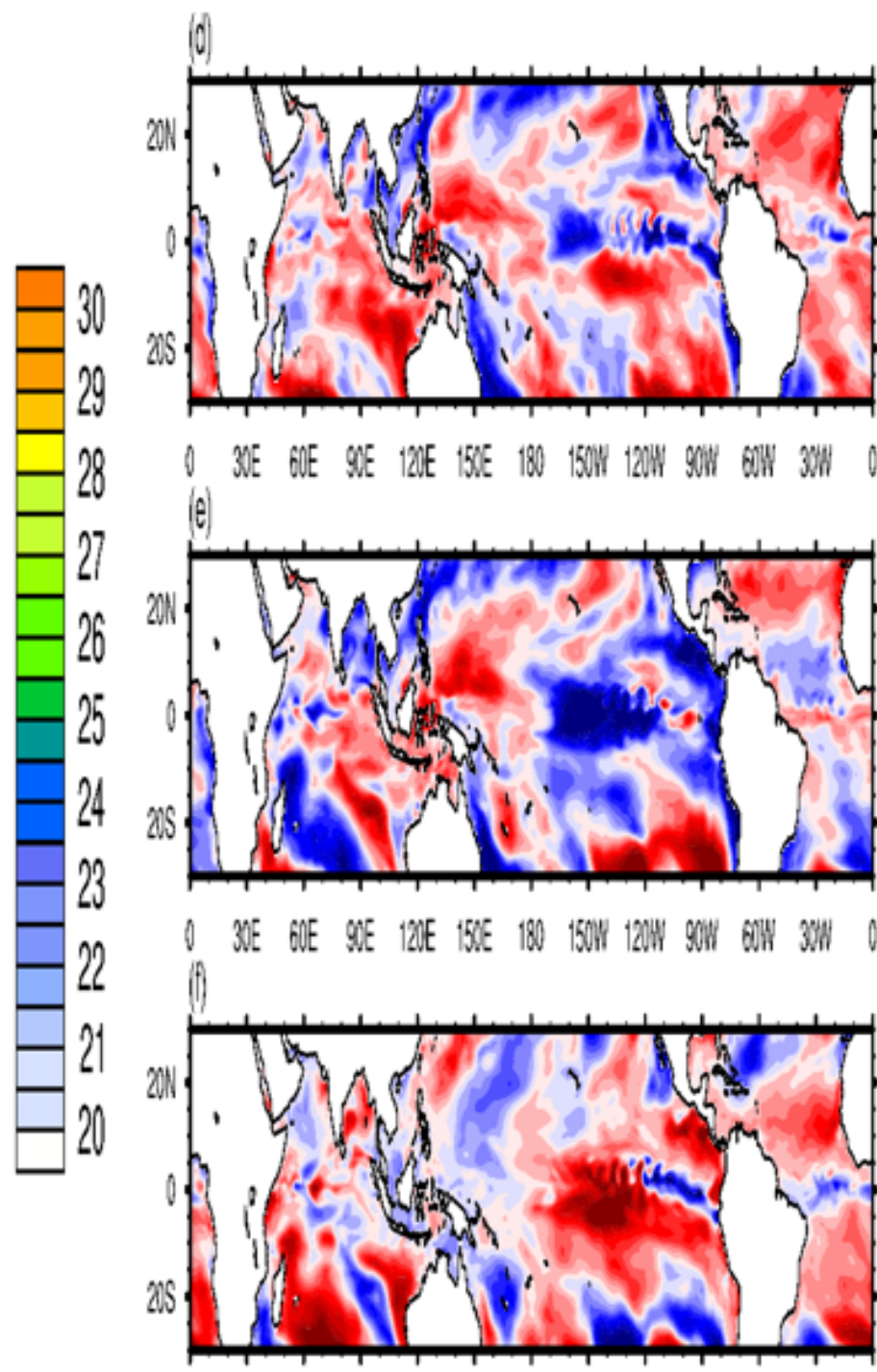

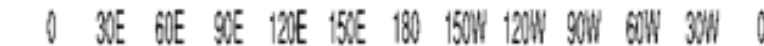
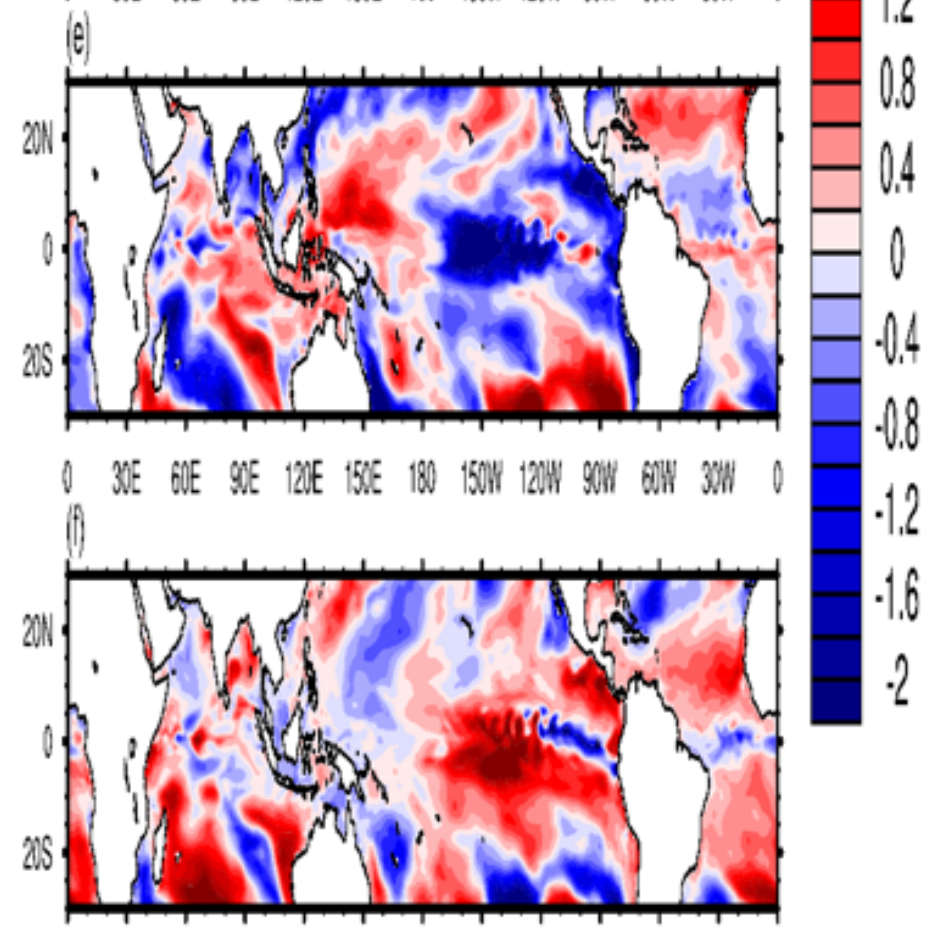

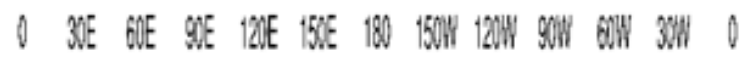

Figure 2

Mean SST for the tropical ocean during (a) pre-NS (December 1957), (b) pre-CE (December 1979), and (c) pre-PE (December 1989) in the model control run. Difference of mean SST for tropical Ocean for different ocean states (d) pre-CE and pre-NS (e) pre-PE and pre-NS, and (f) pre-CE and pre-PE for model control run. 

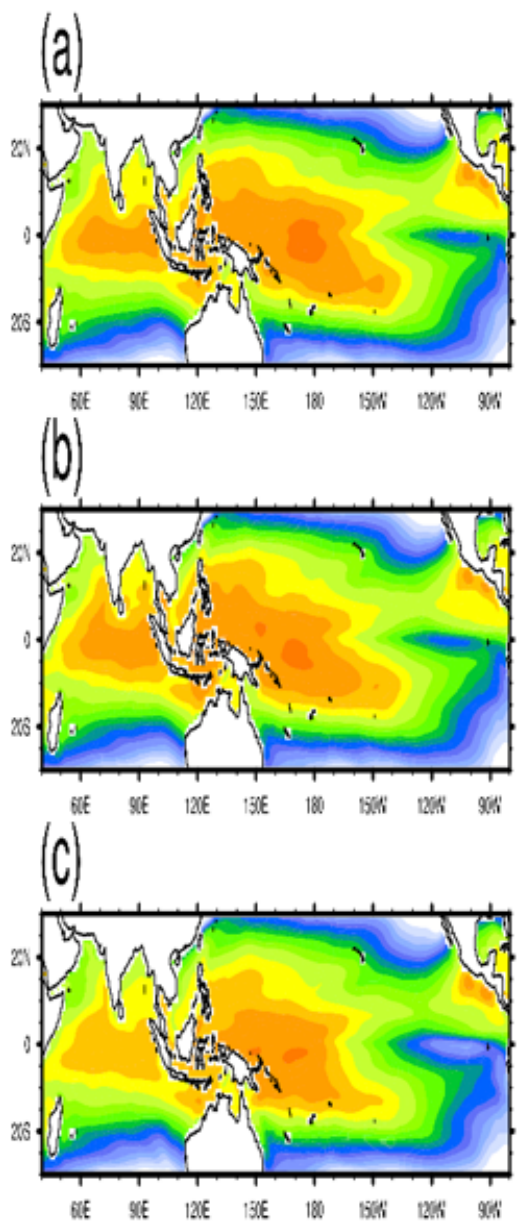

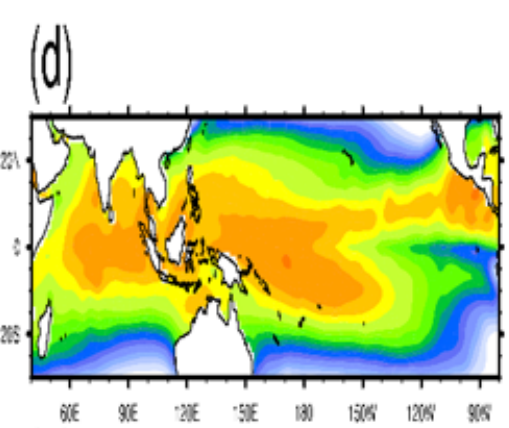

(e)
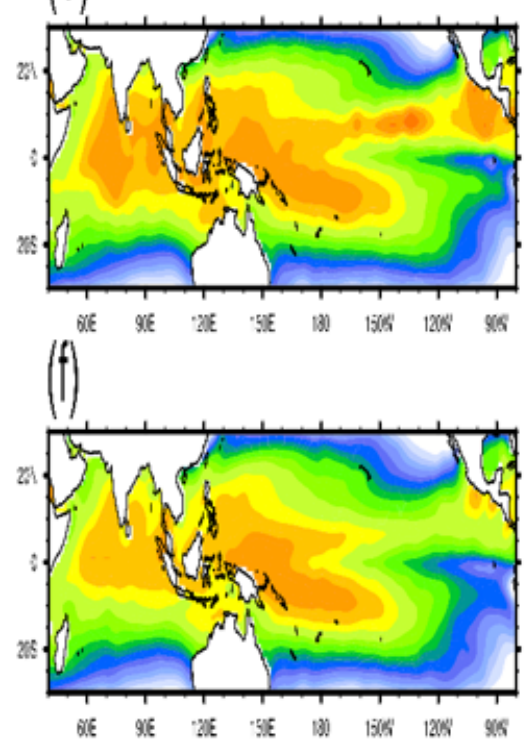

(9)

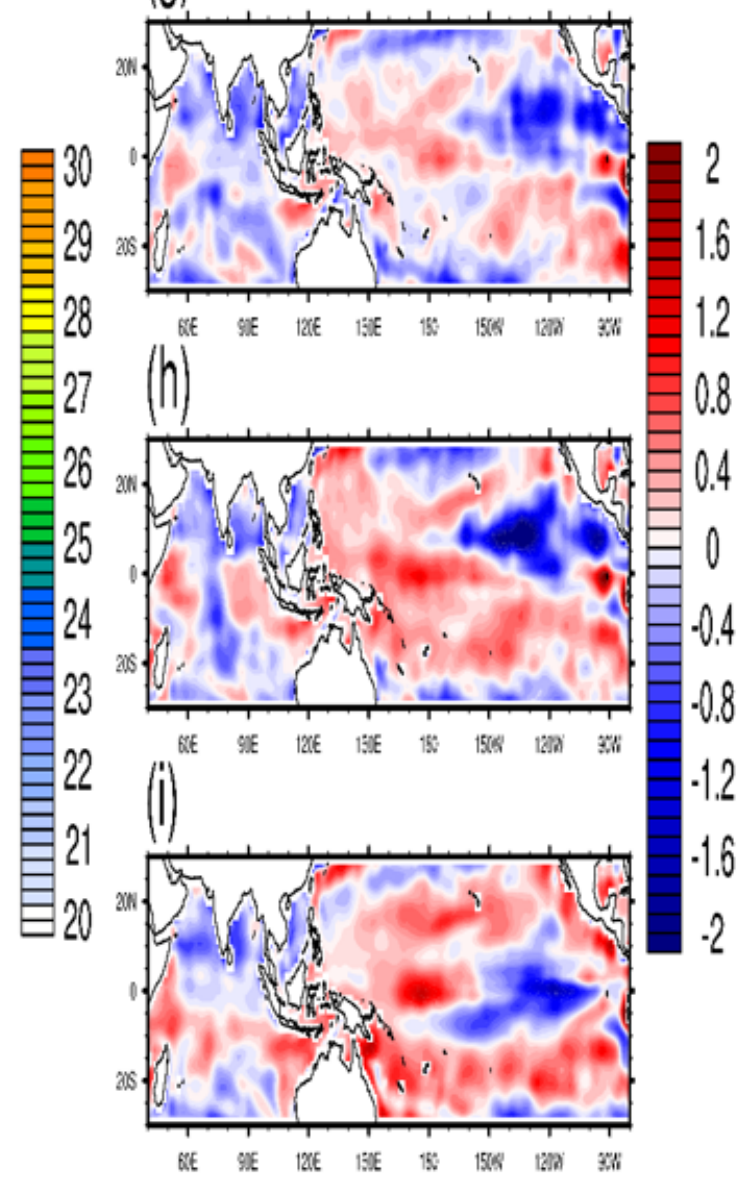

Figure 3

Mean SST for tropical ocean averaged for (a) NS, (b) CE, and (c) PE for model control run. (d-f) same as $(a-c)$ but for observations. ( $g-i)$ shows the difference of SST for model control run (d-f) and observations (a-c) respectively. 
(a)

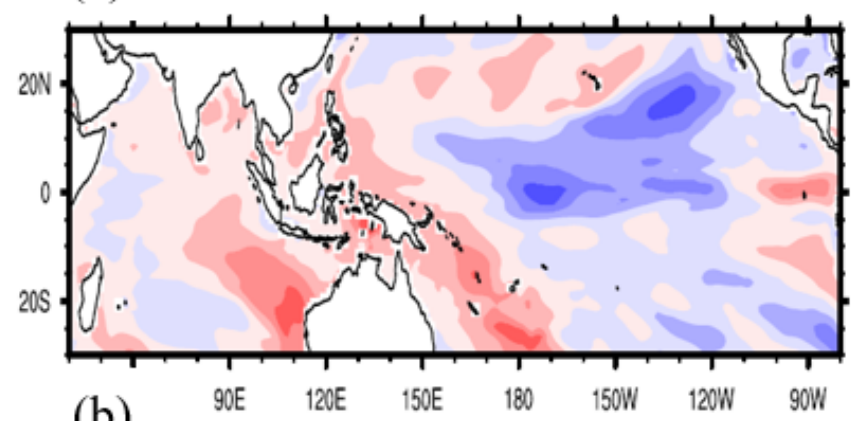

(b)

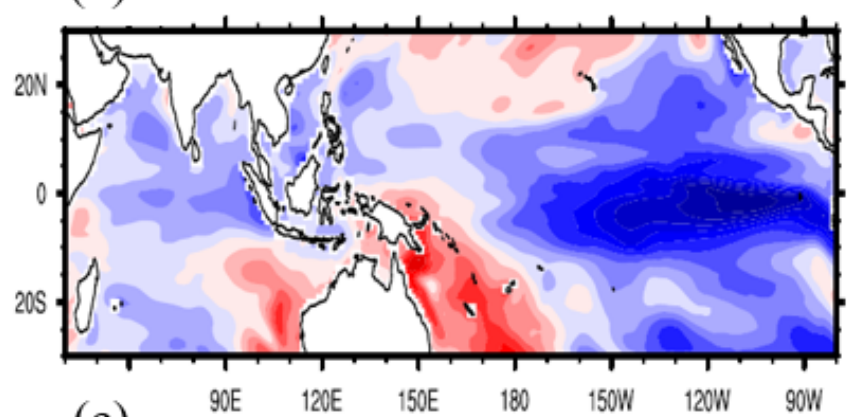

(c)

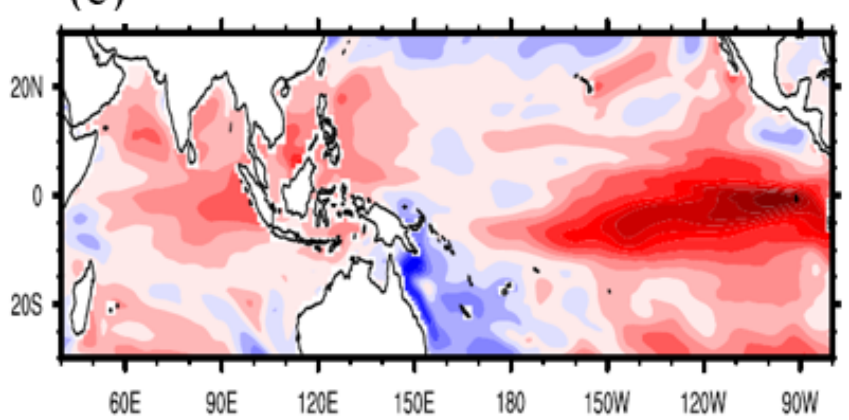

(d)

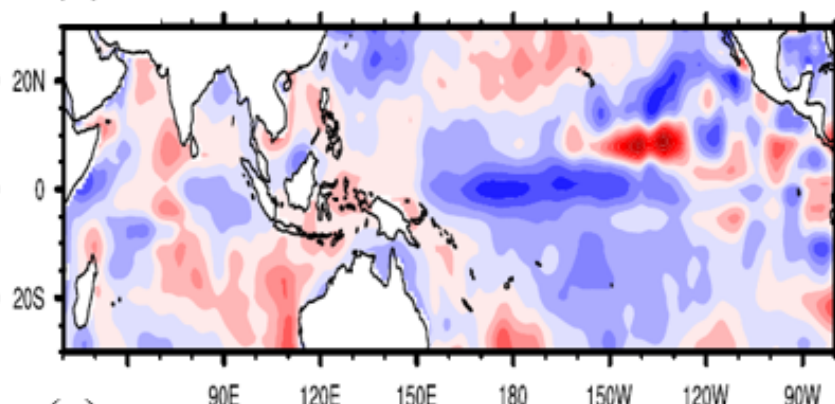

(e)
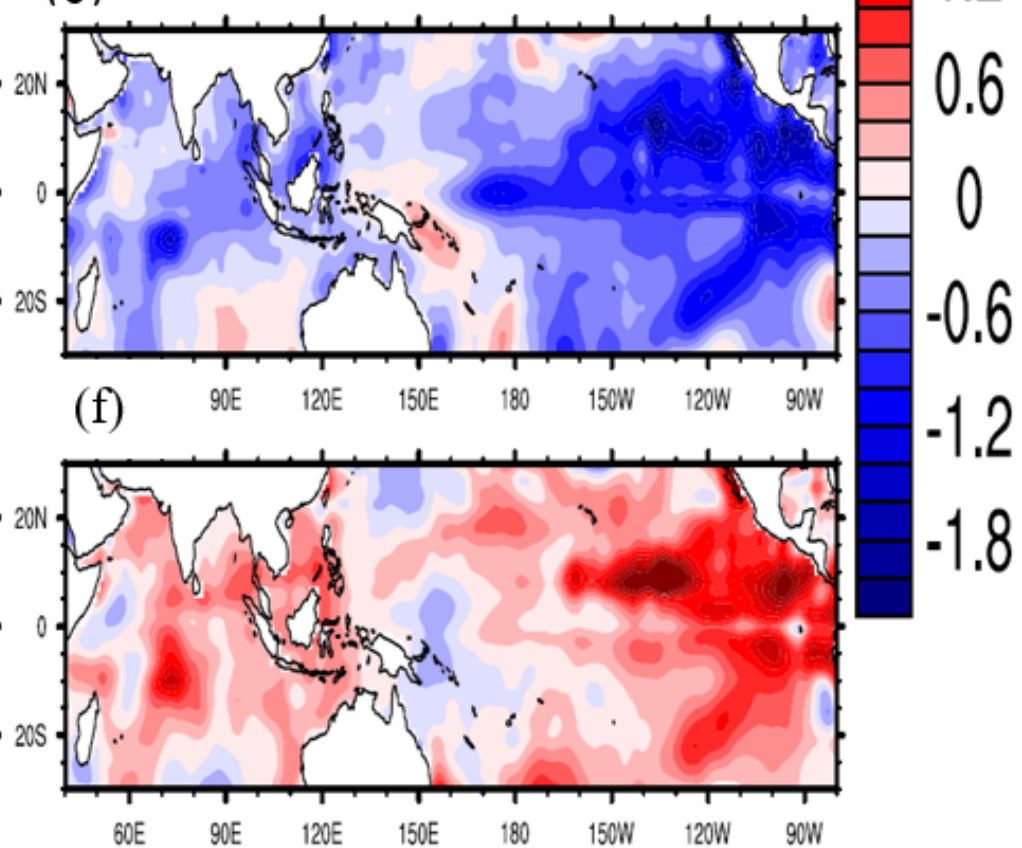

Figure 4

Difference of mean SST for Indo-Pacific Ocean for different ocean states (a) CE and NS (b) PE and NS, and (c) CE and PE for model control run (d-f) same as (a-c) but for observations. 


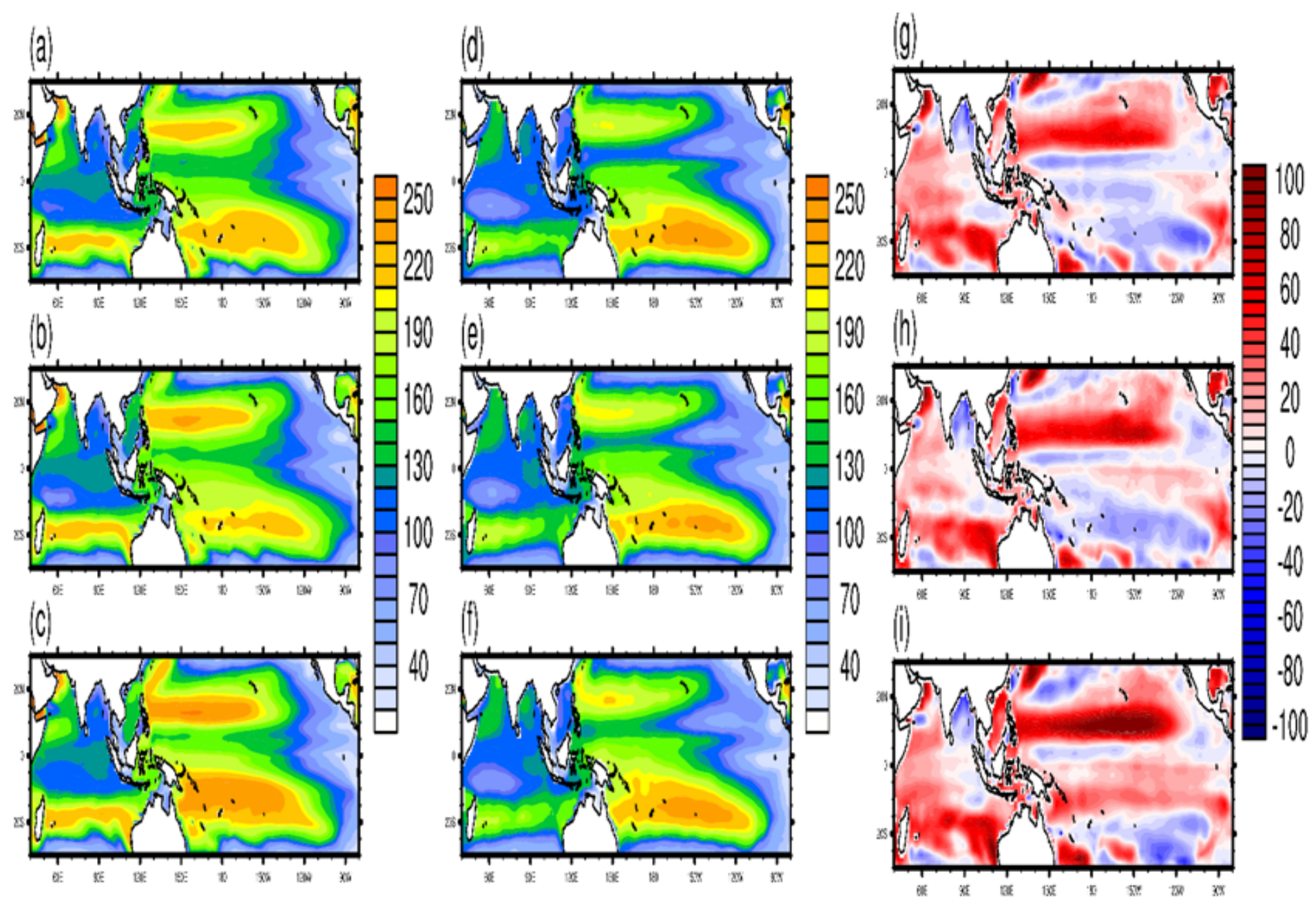

Figure 5

Mean D20 for tropical ocean averaged for (a) NS, (b) CE, and (c) PE for observations. (d-f) same as (a-c) but for model control run. ( $g-i)$ shows the difference of D20 for model control run (d-f) and observations (a-c) respectively. 


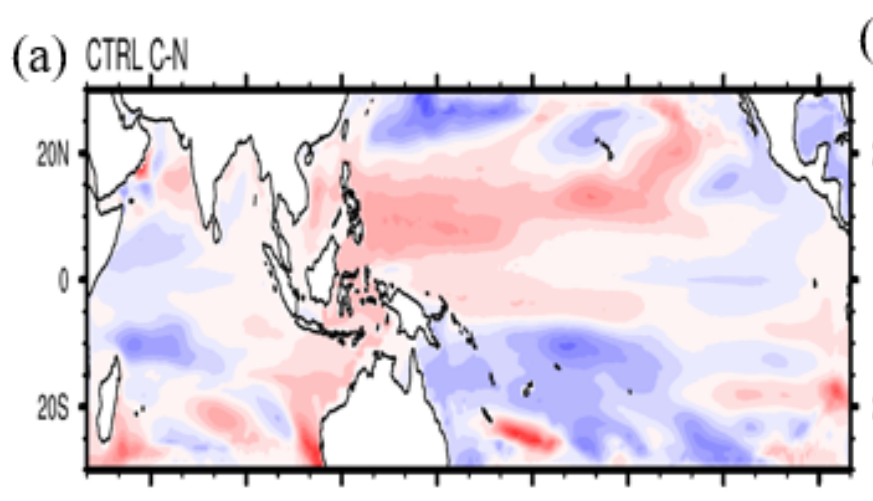

(d) OBSCN
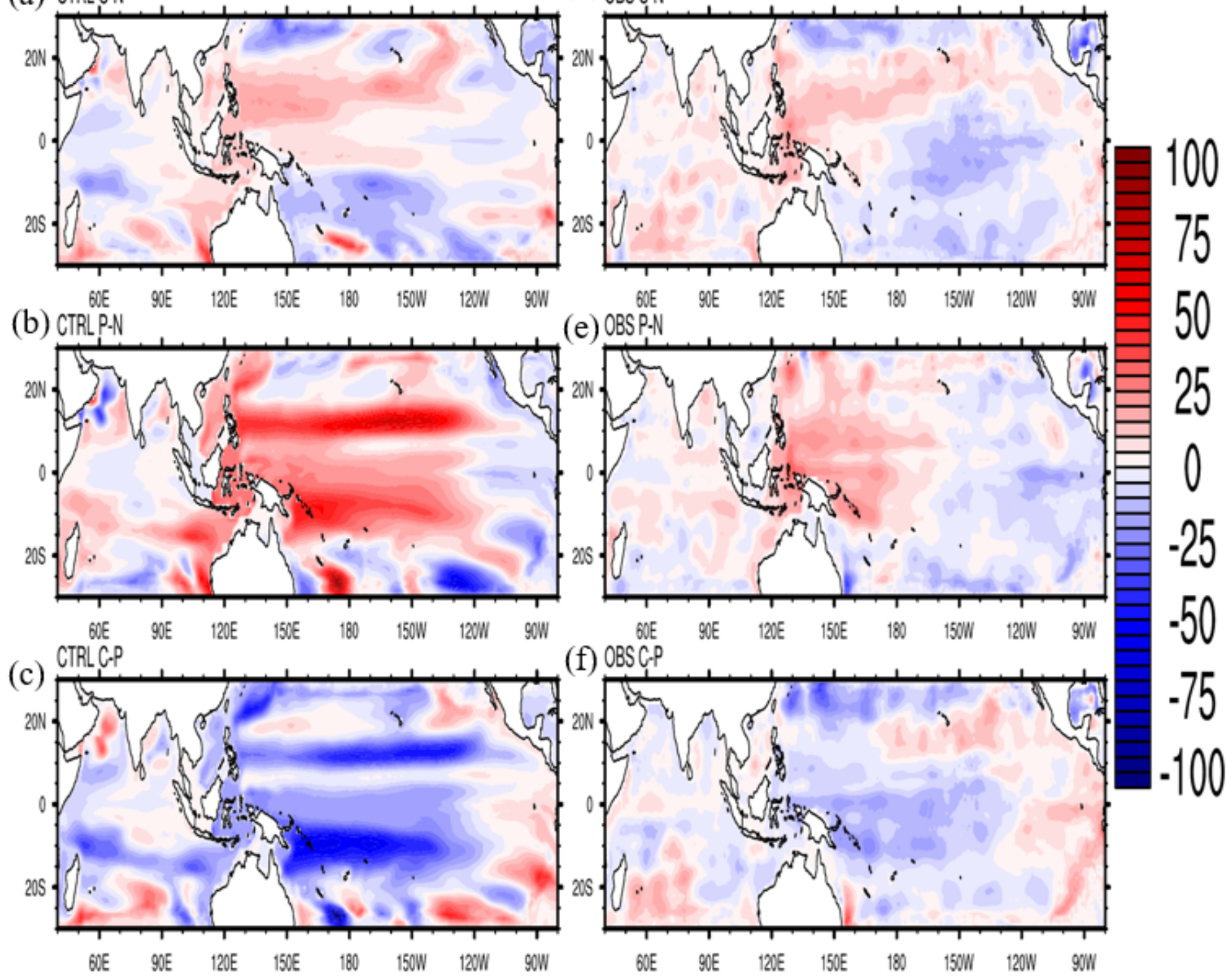

Figure 6

Difference of mean D20 for Indo-Pacific Ocean for different ocean states (a) CE and NS (b) PE and NS, and (c) CE and PE for model control run (d-f) same as (a-c) but for observations. 
Mean U 100-200E,2.5S-2.5N
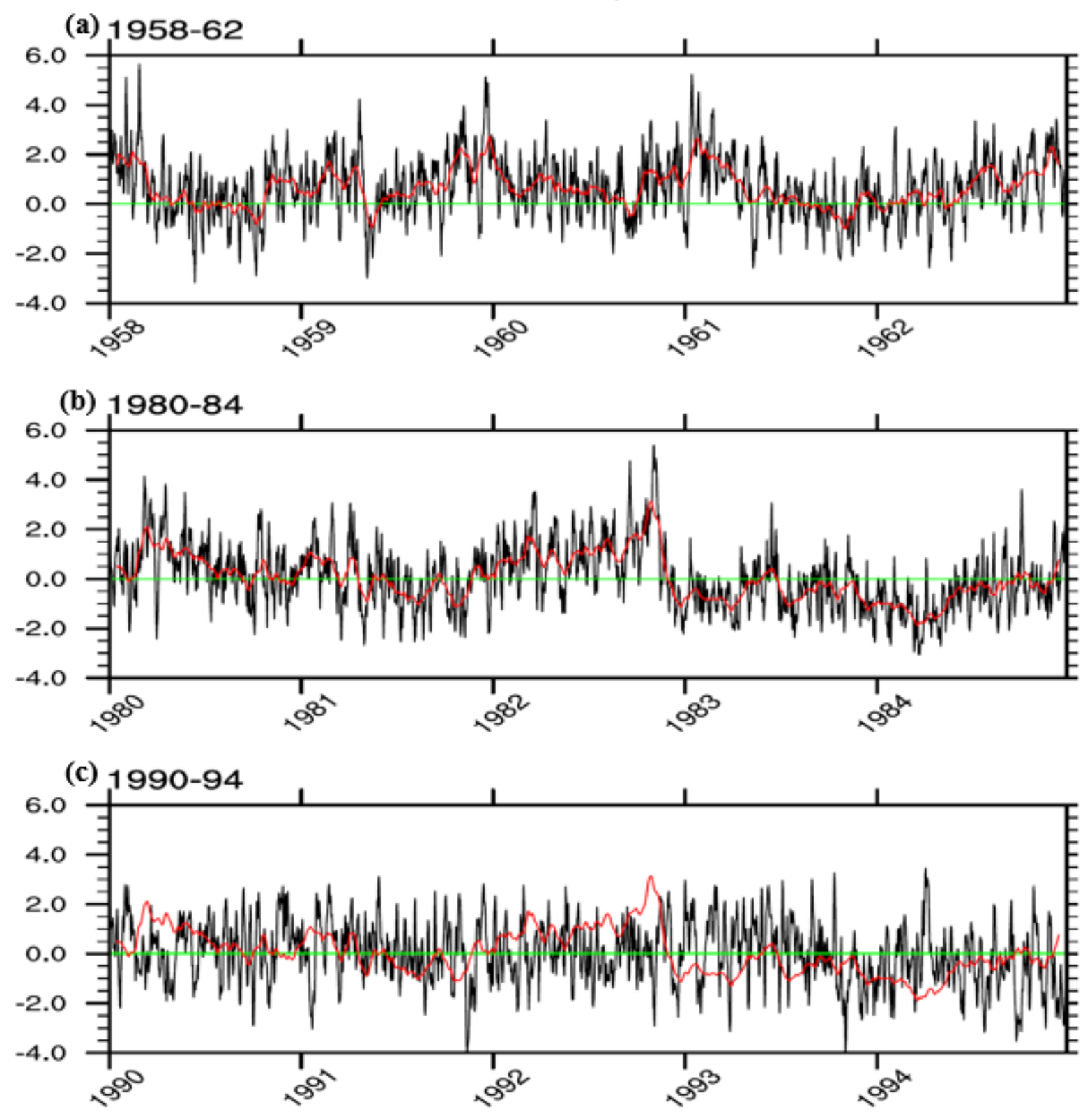

Figure 7

Time series of zonal wind anomaly forcing averaged over western $\mathrm{PO}\left(100-200^{\circ} \mathrm{E}, 2.5^{\circ} \mathrm{S}-2.5^{\circ} \mathrm{N}\right)$ for (a) NS, (b) $C E$, and (c) PE. 


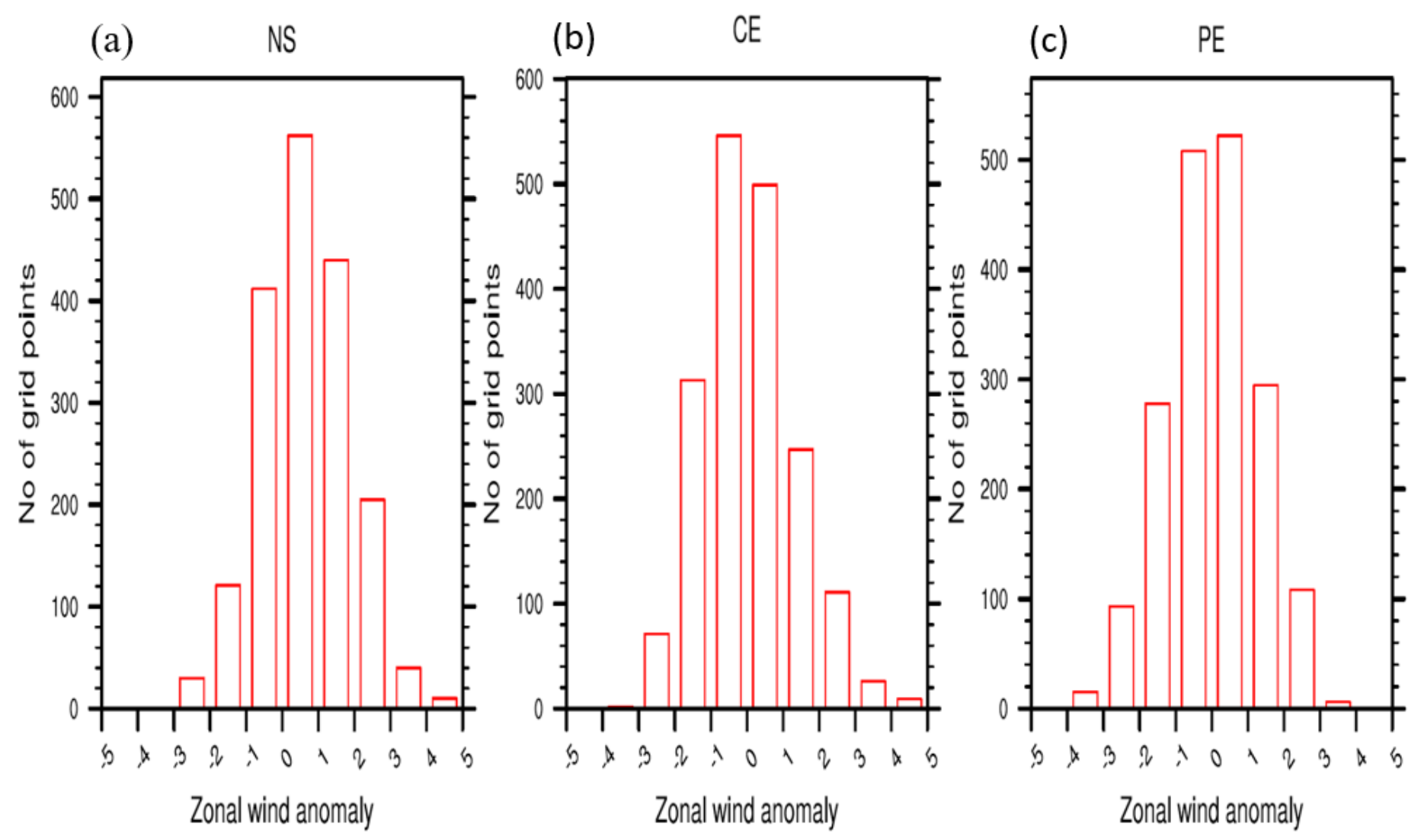

Figure 8

Histogram of Zonal wind averaged over Western PO for (a) NS, (b) CE, and (c) PE. 

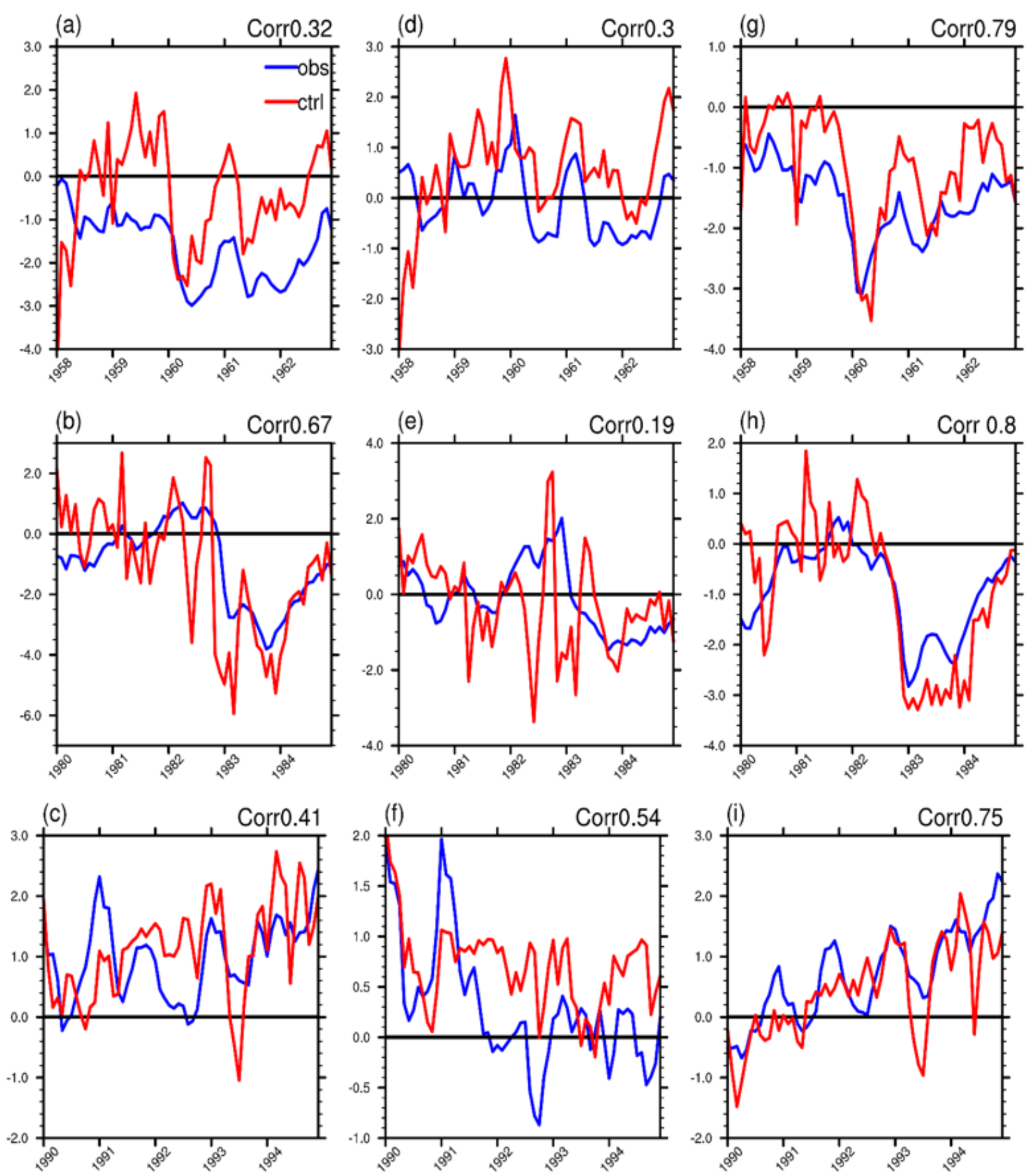

Figure 9

Time series of WWV averaged over for model control run and observations for (a) NS, (b) CE, and (c) PE for TP. (d-f) same as (a-c) but for EP respectively. ( $g-i)$ same as (a-c) but for WP respectively. 

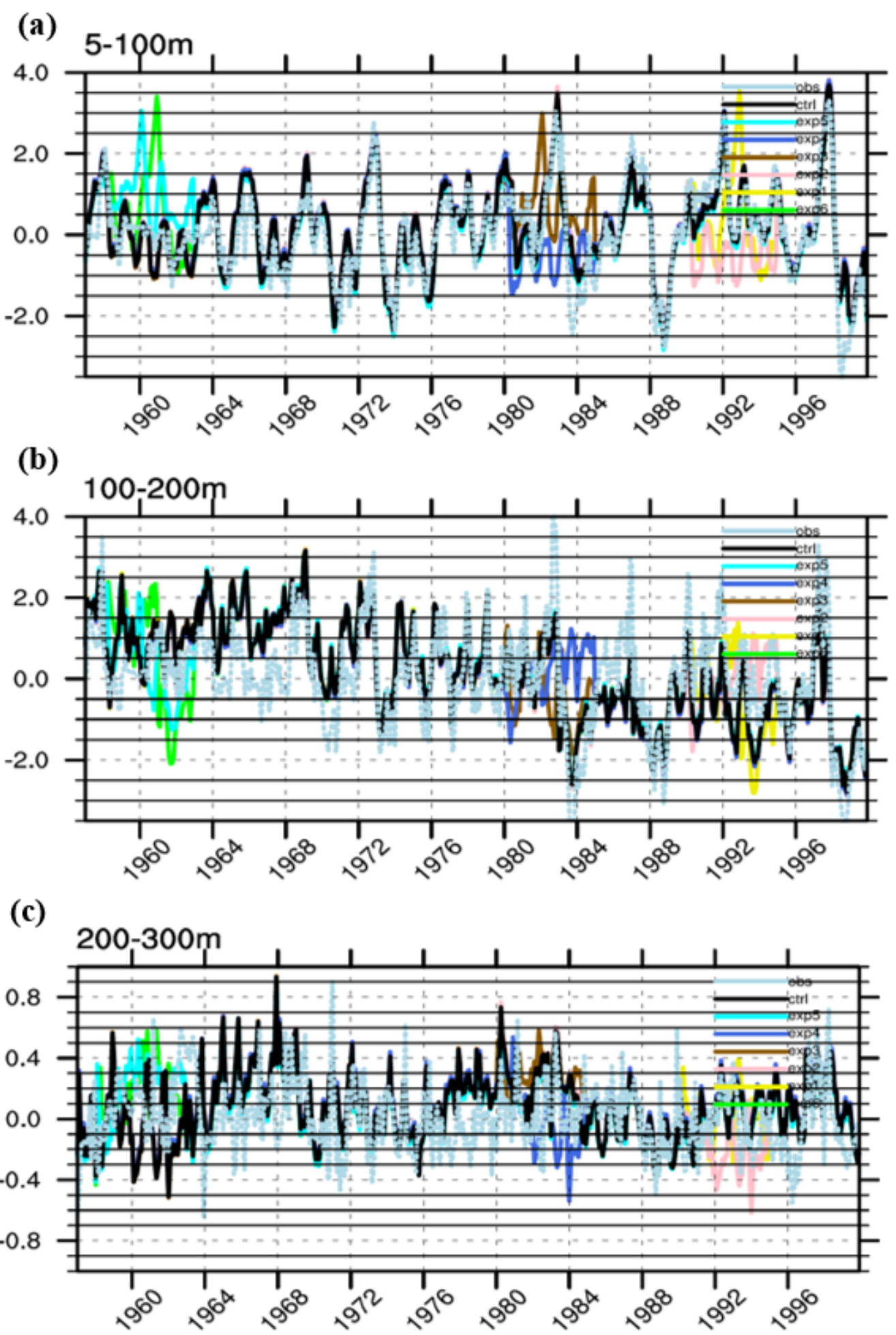

Figure 10

Ocean temperature anomaly averaged over (a) 5-100m, (b) 100-200m, and (c) 200-300m for the period 1956-2000 for model simulations and observations. 


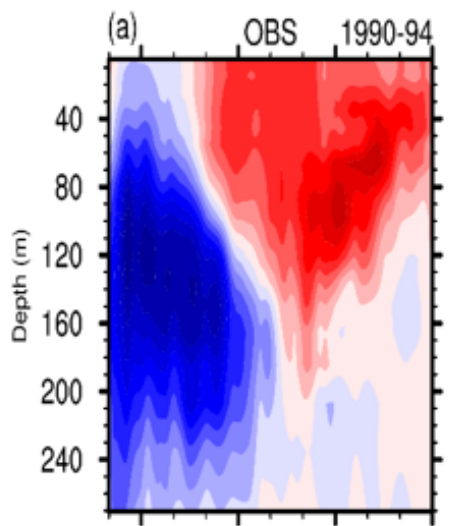

135E $180135 \mathrm{~W} \quad 90 \mathrm{~W}$

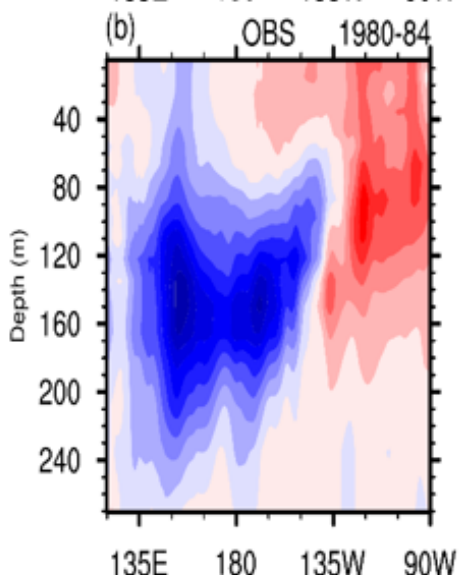

35E 180 135W 90W

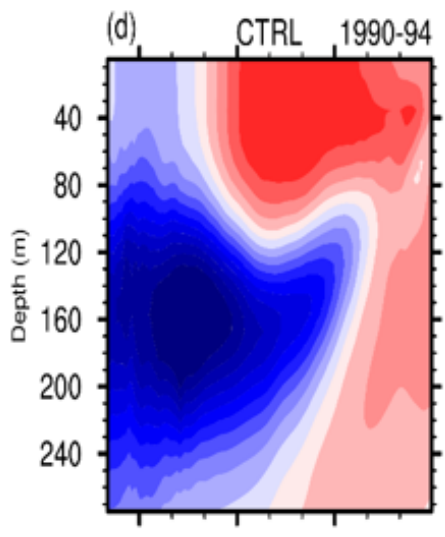

135E $180 \quad 135 \mathrm{~W}$
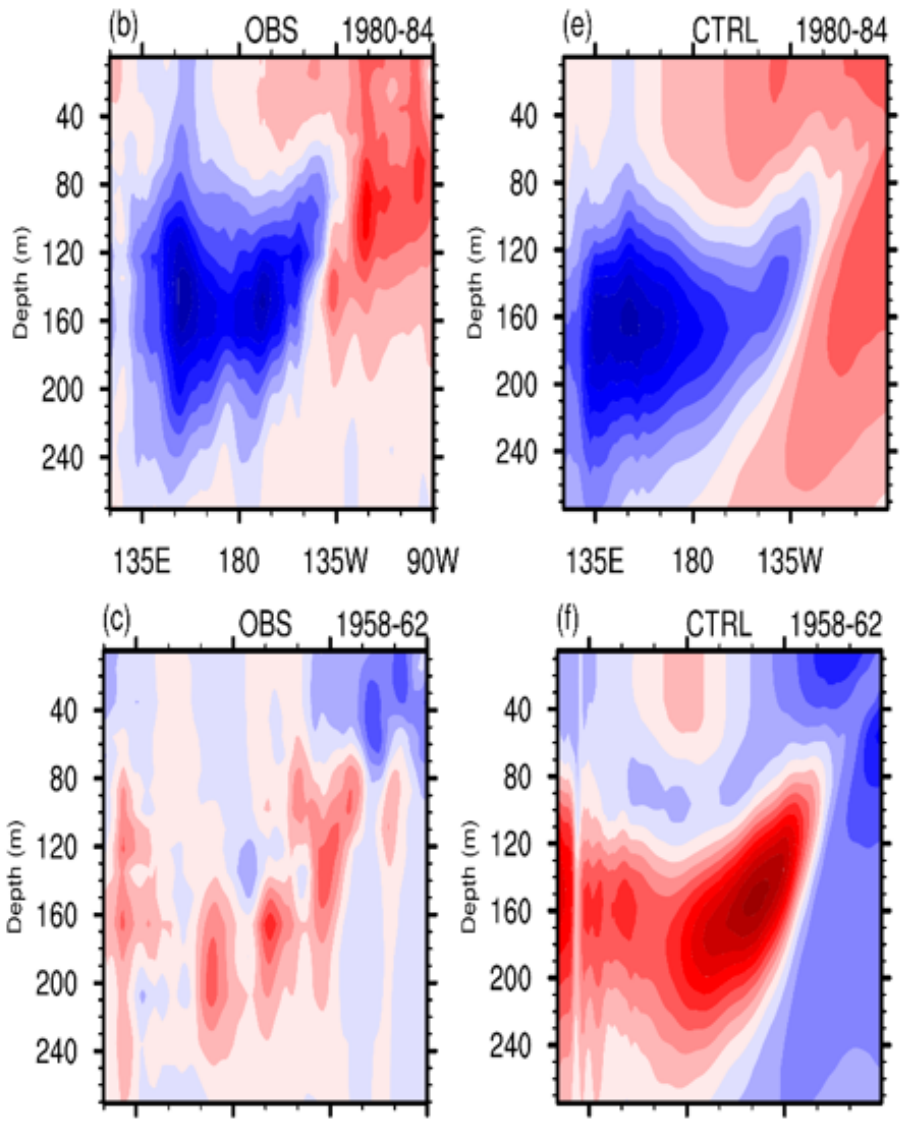

135E $180 \quad 135 \mathrm{~W}$ 90W

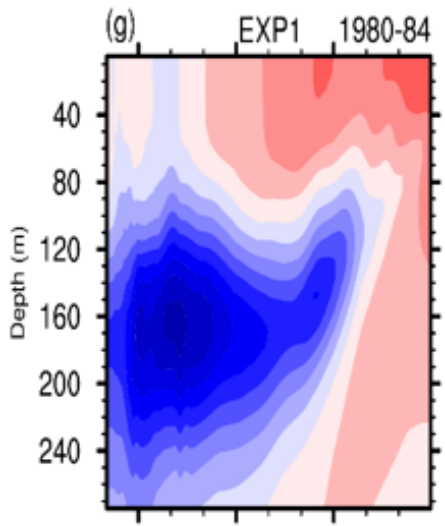

135E $180 \quad 135 W$

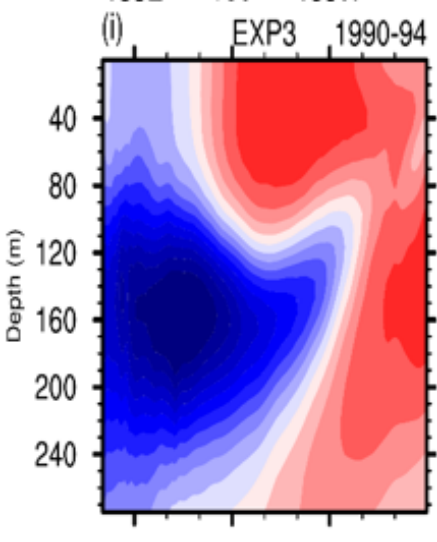

135E $\quad 180 \quad 135 \mathrm{~W}$

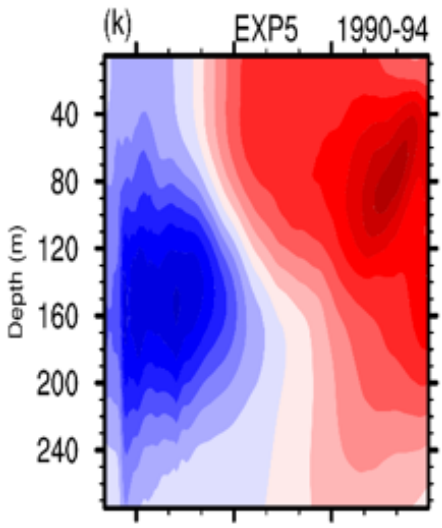

135E $180 \quad 135 \mathrm{~W}$

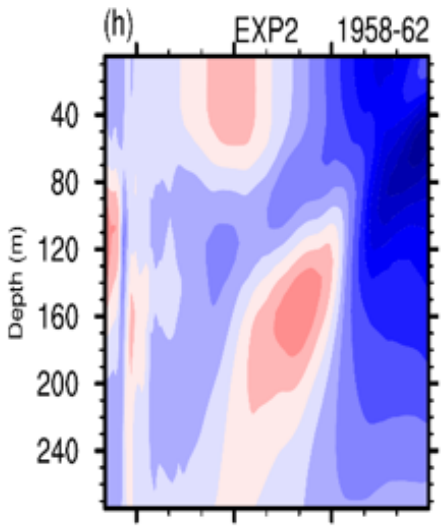

135E $180 \quad 135 \mathrm{~W}$

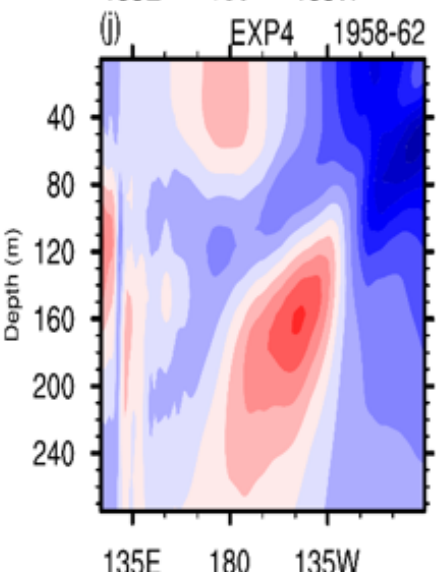

135E $180 \quad 135 \mathrm{~W}$

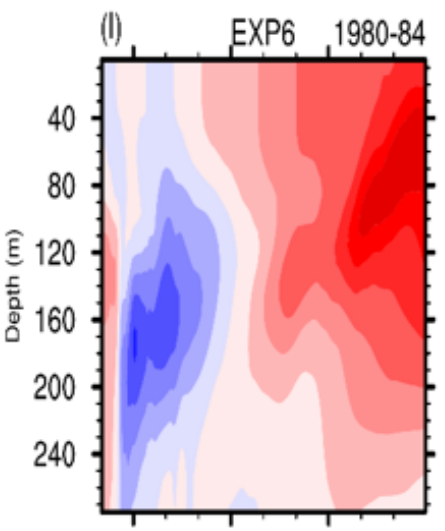

135E $180 \quad 135 \mathrm{~W}$

$$
\begin{array}{lllllllllll}
-2 & -1.6 & -1.2 & -.8 & -.4 & 0 & .4 & .8 & 1.2 & 1.6 & 2
\end{array}
$$

\section{Figure 11}

The subsurface temperature for the upper ocean averaged over $5^{\circ} \mathrm{S}-5^{\circ} \mathrm{N}$ for the Pacific Ocean for (a) PE, (b) CE, and (c) NS for observations. (d-f) same as (a-c) but for model control run. (g-l) shows the subsurface temperature for the upper ocean averaged over $5^{\circ} \mathrm{S}-5^{\circ} \mathrm{N}$ for the Pacific Ocean for model experiments (exp1-exp6) respectively. 